\title{
O Processo de Construção Formativa do Professor Pesquisador em Ensino de Ciências e Matemática: Experiências frente à Pandemia de Covid-19
}

\author{
The Formative Construction Process of the Research Professor in Science and \\ Mathematics Teaching: Experiences in the Face of the Covid-19 Pandemic
}

\author{
Maria Izabel Barbosa de Sousa ${ }^{1}$ \\ Universidade Federal do Amazonas \\ Josseane Costa e Silva ${ }^{2}$ \\ Universidade Federal do Amazonas \\ Evelym Chaves Meireles \\ Kelly Caroline Oliveira ${ }^{4}$ \\ Universidade Federal do Amazonas \\ Luana Monteiro da Costa ${ }^{5}$ \\ Universidade Federal do Amazonas
}

\begin{abstract}
RESUMO
Neste relato, pretendeu-se lançar luz às discussões provenientes do emprego da Roda de Conversa como instrumento metodológico. Para tanto, o momento, planejado para fomentação de reflexões e compartilhamento de vivências e experiências, sucedeu-se por intermédio do diálogo entre as mediadoras, mestrandas do Programa de Pós-Graduação em Ensino de Ciências e Matemática da Universidade Federal do Amazonas, e os discentes ingressantes do Programa. Tais discussões fundamentaram-se no processo de construção formativa continuada do professor pesquisador no Ensino de Ciências e Matemática mediante o cenário pandêmico atual, assim como nos vislumbres acerca dos desafios e posturas exigidas para o exercício docente desse profissional. Após o desenvolvimento da Roda de Conversa, constatou-se que os acadêmicos ingressantes possuíam dúvidas e anseios
\end{abstract}

\footnotetext{
${ }^{1}$ Mestranda no Programa de Pós-Graduação em Ensino de Ciências e Matemática (PPG-ECIM) da Universidade Federal do Amazonas (UFAM), Manaus, Amazonas, Brasil. Endereço para correspondência: Av. General Rodrigo Octavio Jordão Ramos, 1200, Coroado I, Manaus, Amazonas, Brasil, CEP: 69067-005. ORCID iD: https://orcid.org/0000-0003-0939-4467 E-mail: iza.bs.23@gmail.com.

${ }^{2}$ Mestranda no Programa de Pós-Graduação em Ensino de Ciências e Matemática (PPG-ECIM) da Universidade Federal do Amazonas (UFAM), Manaus, Amazonas, Brasil. Endereço para correspondência: Av. General Rodrigo Octavio Jordão Ramos, 1200, Coroado I, Manaus, Amazonas, Brasil, CEP: 69067-005. ORCID iD: https://orcid.org/0000-0001-5190-6855 E-mail: josseane.ead@ gmail.com.

Mestranda no Programa de Pós-Graduação em Ensino de Ciências e Matemática (PPG-ECIM) da Universidade ${ }^{3}$ Mestranda no Programa de Pós-Graduação em Ensino de Ciências e Matemática (PPG-ECIM) da Universidade Federal do Amazonas (UFAM), Manaus, Amazonas, Brasil. Endereço para correspondência: Av. General Rodrigo Octavio Jordão Ramos, 1200, Coroado I, Manaus, Amazonas, Brasil, CEP: 69067-005. ORCID iD: https://orcid.org/0000-0002-7030-358X E-mail: evelymmeireles@ gmail.com.

${ }^{4}$ Mestranda no Programa de Pós-Graduação em Ensino de Ciências e Matemática (PPG-ECIM) da Universidade Federal do Amazonas (UFAM), Manaus, Amazonas, Brasil. Endereço para correspondência: Av. General Rodrigo Octavio Jordão Ramos, 1200, Coroado I, Manaus, Amazonas, Brasil, CEP: 69067-005. ORCID iD: https://orcid.org/0000-0002-0600-434X E-mail: kellycarolineoliveira@ outlook.com.

${ }^{5}$ Mestranda no Programa de Pós-Graduação em Ensino de Ciências e Matemática (PPG-ECIM) da Universidade Federal do Amazonas (UFAM), Manaus, Amazonas, Brasil. Endereço para correspondência: Av. General Rodrigo Octavio Jordão Ramos, 1200, Coroado I, Manaus, Amazonas, Brasil, CEP: 69067-005. ORCID iD: https://orcid.org/0000-0002-8332-8217 E-mail: luanamonteiro.costa@ semed.manaus.am.gov.br.
} 
semelhantes aos apresentados pelas mediadoras, quando estavam na mesma condição, o que viabilizou a promoção de um espaço de interatividade e possíveis soluções para as indagações levantadas pelos participantes.

Palavras-chave: Professor pesquisador; Formação continuada; Pandemia de Covid-19; Roda de Conversa.

\begin{abstract}
In this paper, it was intended to shed light on the discussions arising from the use of the Conversation Wheel as a methodological instrument. Therefore, the moment, planned to encourage reflections and share experiences and experiences, took place through the dialogue between the mediators, master's students of the Graduate Program in Science and Mathematics Teaching at the Federal University of Amazonas, and the students entering the Program. These discussions were based on the continuing formative construction process of the researcher teacher in Science and Mathematics Education through the current pandemic scenario, as well as on glimpses of the challenges and postures required for the teaching practice of this professional. After the development of the Conversation Wheel, it was found that the incoming academics had doubts and concerns similar to those presented by the mediators, when they were in the same condition, which enabled the promotion of an interactivity space and possible solutions to the questions raised by the participants.
\end{abstract}

Keywords/Palabras clave: Research professor; Continuing education; Covid-19 Pandemic; Chat Wheel.

\title{
INTRODUÇÃO
}

A Pandemia de Covid-19 situou a ciência em posição de destaque no mundo inteiro. Por conseguinte, nesse período histórico, o conhecimento científico precisou avançar em todas as áreas do conhecimento.

No campo educacional, desencadeou-se, com mais veemência, a necessidade de reinvenção e adequação do professor, ficando evidente a urgência de uma formação, a qual viabilize uma ação social ativa. Diante disso, os educadores precisaram adequar-se, em um curto período de tempo, às aulas virtuais e, consequentemente, dominar os artefatos tecnológicos (ARRUDA; SILVA; BEZERRA, 2020).

Nesse horizonte, a formação do professor pesquisador, em um cenário pandêmico, também passou por um processo de transformação, dinamização e adaptação, os quais depararam-se com um emaranhado de incertezas em meio ao caos. Sendo assim, tornou-se cada vez mais emergente indagar quais são os saberes necessários à prática educativa do professor frente ao plano pandêmico, de modo a alinhar os conhecimentos científicos com a prática docente.

Em cenários educacionais adversos, tal como o estabelecido na pandemia, origina-se a oportunidade para discutir-se, criticamente, sobre a formação do educador na condição de pesquisador. Partindo desse princípio, os professores têm um papel importante frente às mudanças da sociedade, logo, é preciso repensar as exigências que circundam a profissão docente, considerando a complexidade que se agiganta na sociedade contemporânea e, consequentemente, na Educação (SONNEVILLE; JESUS, 2009).

Discutindo a responsabilidade que a ciência, ou melhor, o pesquisador tem perante a sociedade e o homem, Morin (2005) advoga que o conhecimento, ao invés de ser armazenado, 
Caderno de Pesquisa em Ensino

de Ciências e Matemática

deve ser pensado e refletido. Tal ponto reforça o papel desse profissional, levando em consideração o contexto que se vive atualmente e suas implicações para os campos científicos e educacionais, ademais, evidencia que o saber, seja em produção na pesquisa ou já consolidado, abordado na escola, precisa passar pelo crivo da reflexão e crítica para não perder seu sentido ou sua função social.

Em se tratando do professor pesquisador atuante na pesquisa e no Ensino de Ciências, o perfil dos sujeitos participantes da experiência deste relato, tangenciam as repercussões acerca de uma formação crítica e reflexiva, condizente com as demandas sociais e educacionais da atualidade, as quais são ainda mais diretas e emergentes.

Perante o exposto, esse relato tem como principal objetivo descrever um momento construído com discentes ingressantes de um Programa de Pós-Graduação em Ensino de Ciências e Matemática por meio de uma Roda de Conversa, na qual refletiu e discutiu-se sobre a formação do pesquisador em Ensino de Ciências frente ao contexto da Pandemia de Covid19.

\section{A FORMAÇÃo dO PROFESSOR PESQUISADOR MEDIANTE O CENÁRIO PANDÊMICO}

Diante do panorama educacional derivado da pandemia, torna-se imprescindível realizar reflexões sobre as diferentes esferas da formação e prática docente do agente de transformação. Ao encontro dessa visão, a formação prática desse profissional reflexivo não deve se alicerçar no paradigma da racionalidade técnica e neopositivista, já que estas não fomentam os artifícios essenciais para lidarmos com fenômenos práticos, tais como a complexidade e incertezas subjacentes à pandemia, enlaçando todas as dimensões que compõem o ser humano (CASTRO; BARROS; BARRETO, 2016).

Tais dimensões transitam entre aspectos emocionais, políticos, éticos, reflexivos e críticos, envolvendo aspectos pessoais e sociais. Haja vista, a Educação Científica, direcionada à compreensão do fato científico, deve ser aliada de um professor qualificado e instruído para dominar não apenas o conhecimento conceitual científico, contudo, outras competências e habilidades, bem como uma visão política que proporciona a transformação social, a qual salienta sua importância. Em virtude disso, considerar a Educação Científica é crucial para o desenvolvimento de ações efetivas, a fim de diminuir os impactos gerados pela pandemia (CASTRO; BARROS; BARRETO, 2016).

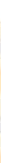


A reunião desses aspectos pode favorecer a ação reflexiva diante do que está justaposto, propiciando ao professor pesquisador o domínio de novas metodologias, englobando múltiplos saberes. Acerca disso, Tardif (2011) acentua que o repositório de saberes profissionais docentes se trata de um movimento evolutivo e transformativo, o qual passa por sedimentações sucessivas ao longo da história de vida e da carreira desses professores, sendo que essas histórias e carreiras remetem às inúmeras camadas de interações e recomeços.

Uma das grandes constatações no campo da Educação, que a pandemia de Covid-19 escancarou, diz respeito à necessidade de impulsionar um processo formativo cada vez mais multifacetado em conformidade com as condições discutidas anteriormente. Isso posto, a fim de reagrupar tais saberes para a compreensão do contexto educacional e buscar um entrelaçamento e intersecções entre os fatos apresentados - com foco na formação do professor pesquisador mediante à conjuntura pandêmica e nas diferentes questões científicas adjacentes que se agigantam -, nos embasaremos nas ideias propostas por Edgar Morin para as discussões a seguir.

Ao discutir a ciência com consciência, Morin (2005) preconiza que a ciência é, intrínseca, histórica, sociológica e eticamente complexa, de modo que é crucial saber reconhecer e lidar com essa complexidade. Atuante no cenário educacional mundial, contribuindo com os diálogos construídos sobre a Educação Contemporânea, o autor postula sobre a complexidade e necessidade do pensamento complexo na tentativa de conectar as informações contidas em situações diferentes, uniformizando as partes e possibilitando, portanto, a compreensão do todo.

A articulação entre as unidades complexas e os aspectos sociais que envolvem o ser humano são multidimensionais. Nesse viés, o paradigma da complexidade, advogado por Morin (2005), não formula e, muito menos, predetermina uma inteligibilidade, visto que se pode incitar a estratégia/inteligência do sujeito pesquisador a partir da complexidade do objeto e questão estudada.

Desse modo, deve-se distinguir, interagir e divulgar, ao contrário de isolar e fragmentar, reconhecendo os traços ímpares, intrínsecos, peculiares, históricos, entre outros, de determinado fenômeno, para não reduzi-lo a uma mera ligação aleatória de determinações ou leis gerais. Em outras palavras, prima-se por uma relação entre unidade e multiplicidade de tal fenômeno em vez de heterogeneizar ou desmembrar suas categorias ou uniformizá-las em sua 
Caderno de Pesquisa em Ensino

de Ciências e Matemática

totalidade, assim, torna-se indispensável considerar todos os caracteres multidimensionais da realidade estudada (MORIN, 2005).

Por fim, para o teórico, o conhecimento construído deve evidenciar as características humanas destacando o ser biológico, psíquico, social, afetivo e racional, bem como as particularidades sociais, como as dimensões histórica, econômica, sociológica e religiosa. Nesse contexto, é interessante perceber que o professor pesquisador assume características do ser humano devendo ser considerado, no seu processo formativo, todas as esferas que circundam a vida diária do ser complexo (MORIN, 2005).

Em vista disso, esse profissional está inserido em uma sociedade multidimensional, o qual precisa entender a complexidade do prisma educacional estabelecido, inteirando-se às novas demandas à medida que as experiências concretas lhes possibilitem uma ação reflexiva para ressignificar sua prática. A teoria da complexidade direciona-se, opostamente, à fragmentação humana, educacional e científica, o complexo, por sua vez, propõe a conexão entre sistemas que envolvem o ser humano, a sociedade, a história e a ciência, sendo útil à compreensão das estruturas constituintes do plano moderno imerso na pandemia (MASSONI; MOREIRA, 2017).

Haja vista, o ser humano, como agente social, faz parte de sistemas complexos, executando ou sofrendo ação em meio coletivo, assim sendo, as relações estipuladas na contemporaneidade só ratificam que vivemos em redes interligadas a sistemas biológicos, como a transmissão de doenças infectocontagiosas, e sistemas educacionais. Frente aos fatos discutidos, as redes de informações científicas foram construídas e solidificadas, mesmo em um cenário negacionista observado em várias partes do mundo, tornando frutíferas as discussões e diálogos propostos pela teoria da complexidade com vistas à formação do professor pesquisador.

\section{EDUCADOR CIENTÍFICO: DESAFIOS E POSTURAS INERENTES AO EXERCÍCIO DOCENTE}

O processo de formação profissional de professores e pesquisadores de Ensino de Ciências e Matemática constitui-se como um movimento abrangente e contínuo, que exige incessantes reflexões às práticas pedagógicas e metodológicas de ensino. Nesse horizonte, Carvalho e Gil-Pérez (2011) voltaram suas pesquisas para o estudo e evidência das necessidades formativas que circundam esse processo, o qual deve ocorrer de modo significativo.

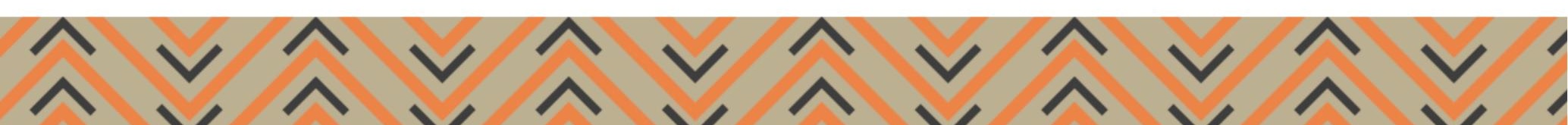


Em virtude disso, ao realizarem investigações com professores de Ciências, perceberam que quando questionados acerca das competências e habilidades indispensáveis à prática profissional, no quesito "saber" e "saber fazer", esses educadores sentem-se inseguros e confusos, fornecendo respostas, evidentemente, supérfluas. A partir disso, os autores imergiram em uma profunda reflexão referente ao distanciamento do professor de Ciências das inovações didáticas e pesquisas voltadas para o ensino.

Por essa ótica, tal distanciamento traduz-se como um fator de banalização da profissão docente, reduzindo à atuação do professor a “[...] um bom conhecimento da matéria, algo de prática e alguns complementos psicopedagógicos.” (CARVALHO; GIL-PÉREZ, 2011, p.14). Diante disso, ressaltam que essa visão simplista assola a docência e ocasiona consequências diretas no Ensino de Ciências, como a cultivação do ensino tradicional, o qual reforça uma visão inatingível, imutável, dogmática e algorítmica da ciência (CACHAPUZ et al., 2005).

A propagação dessa imagem de ciência, consequentemente reducionista, origina desafios à formação de professores e pesquisadores, visto que tais concepções refletem, diretamente, na prática pedagógica de cada um deles. Partindo desse princípio, Costa et at. (2017) preconizam que muitas dessas visões distorcidas acerca da ciência podem ser evitadas através de uma formação inicial adequada, demonstrando novos caminhos para o Ensino de Ciências, a partir de uma formação dialética, cidadã, política, humanitária e democrática, a qual divulga uma ciência em construção e ação.

Em aproximação, Carvalho e Gil-Pérez (2011) apresentam algumas das necessidades formativas que, efetivamente, precisam ser desenvolvidas pelo educador científico. A primeira consiste no rompimento das visões simplistas de ensino, cuja finalidade é transformar as concepções do professor acerca de sua prática didático-pedagógica, já a segunda diz respeito ao conhecimento específico do componente curricular a ser ensinado.

Apesar de a última necessidade transmitir traços de um ensino tradicional, os autores argumentam em prol de sua inevitabilidade, longe de formar transmissores de conteúdo mecânicos, não obstante, profissionais que compreendam e saibam ensinar conteúdos técnicocientíficos. Para mais, precisam levar em consideração o âmbito histórico-epistemológico da ciência, às orientações didático-metodológicas de ensino, a relação Ciência, Tecnologia, Sociedade e Ambiente, entre os demais aspectos que devem ser sublinhados no processo de ensino e aprendizagem. 
Caderno de Pesquisa em Ensino

de Ciências e Matemática

Nesse seguimento, adquirir conhecimentos teóricos sobre a aprendizagem das Ciências também constitui uma capacidade do professor de Ciências, a qual deve possibilitar a construção de propostas didáticas construtivistas que resultem em uma aprendizagem significativa por parte do aluno. Em outras palavras, torna-se crucial que esse educador, constantemente, modifique/complemente sua prática habitual em sala de aula, com o objetivo de atender às demandas educacionais que perpassam/ultrapassam os portões das escolas, amenizando possíveis obstáculos na construção do conhecimento CARVALHO; GIL-PÉREZ, 2011).

Ainda, para além da formação inicial, também é primordial que o professor pesquisador adote uma postura reflexiva frente aos desafios citados. No contexto do Ensino de Ciências, o professor reflexivo deve ser aquele que além de refletir sobre sua ação e práxis metodológica, busca por soluções alternativas que ressignifique a imagem distorcida que os alunos possuem acerca da ciência. Para Schon (2000), as práticas reflexivas ocorrem por meio de três conceitos primordiais - reflexão na ação, reflexão sobre a ação e a reflexão sobre a reflexão na ação -, dado que a prática desses conceitos possibilita o ato de identificar e, posteriormente, lidar com os problemas e desafios encontrados no decorrer do exercício docente.

Ainda, no que tece os saberes e necessidades formativas, destacamos a inevitabilidade de uma formação inicial e continuada que contemple, tal como advogam Mishra e Koehler (2006), o desenvolvimento de competências digitais docentes relacionadas ao conhecimento tecnológico e pedagógico do conteúdo. Nesse prisma, o professor pesquisador precisa construir competências acerca das Tecnologias de Informação e Comunicação (TICs), as quais tecem a investigação, reflexão e o desenvolvimento de uma análise crítica, tanto para compreender e empregá-las quanto para formular soluções tecnológicas que guiem uma prática pedagógica coerente, ética, dinâmica, desafiadora, significativa e humana.

Nessa direção, a pandemia clarificou o quanto o professor de Ciências precisa dominar recursos metodológicos e tecnológicos, visto que perante contextos e variáveis imprevisíveis, torna-se essencial adaptar e aprimorar-se cada vez mais. Tais artifícios podem ser manuseados para promover uma formação, também tecnológica, que valorize a comunicação, disseminação de informações úteis e conscientizadoras, produção e potencialização de conhecimentos, não somente científicos, e a resolução de problemas que circunscrevem o cotidiano e a sala de aula (DIAS-TRINDADE; SANTO, 2021).

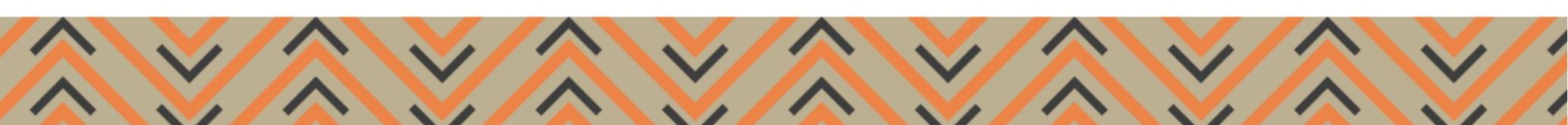


Do exposto, com base na atual conjuntura que se agiganta em nossa sociedade, esperase do profissional da área de Ensino de Ciências que lhe seja assegurada uma formação inicial e continuada que atenda as principais necessidades do ambiente, no qual estamos imersos, desenvolvendo capacidades, disposições e atitudes, que o preparem para os obstáculos e situações inusitadas, diferentes daquelas que presenciou no ambiente acadêmico. Assim sendo, de modo geral, é emergente que agregue ao seu repertório profissional características, tais como: adaptação; improviso; dinamismo; autonomia; protagonismo; empatia; ética; compromisso social; respeito.

\section{METODOLOGIA}

Nesta pesquisa, adotou-se uma abordagem do tipo Qualitativa, em razão de atribuir importância, predominantemente, aos depoimentos dos sujeitos envolvidos no processo investigado, assim como as suas interpretações, vivências e experiências acerca da temática debatida. Em vista disso, utilizou-se a Roda de Conversa como um instrumento metodológico na perspectiva de estimular um ambiente para que as trocas de experiências e reflexões coletivas ocorressem de modo fecundo segundo a percepção de cada indivíduo (ALVES-MAZZOTTI; GEWANDSZNAJDER, 2000; WARSCHAUER, 2017).

Ainda, a Roda de Conversa foi empregada, com a finalidade de permitir, por meio das características de cada participante, a expressão de impressões, opiniões e concepções sobre o tema em questão. A interação entre as mediadoras desse momento e os participantes da pesquisa possibilitou o surgimento de um espaço regado de diálogo, escuta e compreensão - sem invadir e manipular - das diferentes vozes que dali jaziam, constituindo um processo não-diretivo, dialético e democrático, com opiniões convergentes e/ou divergentes, a fim de compreender e transformar o meio, no qual os sujeitos participantes atuam (FREIRE, 2005).

No mais, ressalta-se que foram adotados os cuidados metodológicos, tal como preconizado Gatti (2005), os quais dizem respeito a preocupação que os condutores devem estabelecer para manter o foco do assunto em pauta, possuindo diligência para saber quando retomar ou prolongar discussões de acordo com os objetivos propostos para o momento. No entanto, é crucial que isso ocorra de modo natural através de um clima amigável, para que os participantes se expressem livremente.

Neste estudo, a Roda de Conversa, intitulada "O Processo de Construção Formativa do Professor Pesquisador em Ensino de Ciências e Matemática frente à Pandemia de Covid-19”, ocorreu na Semana de Acolhida para os calouros do Programa de Pós-Graduação em Ensino de 
Caderno de Pesquisa em Ensino

de Ciências e Matemática

Ciências e Matemática (PPG-ECIM) da Universidade Federal do Amazonas (Ufam), de modo virtual, pela Plataforma Zoom Meetings ${ }^{6}$. O momento durou por volta de uma hora e meia, contando com a participação de 19 mestrandos, cujo ingresso ocorreu no ano de 2021.

É válido ressaltar que, antes do desenvolvimento da Roda, foi enviado o link de um questionário on-line, via Google Forms ${ }^{7}$, aos acadêmicos, com o intuito de: sinalizarem o seu desejo em participar da dinâmica; indicarem quais temas demonstravam-se interessantes para discutir-se na roda; conhecer, previamente, um pouco dos sujeitos que compuseram o momento.

Sendo assim, dividiu-se o instrumento em três itens: 1) Curso de Formação Inicial dos mestrandos; 2) Expectativas/Desafios para o desenvolvimento do Mestrado; 3) Temáticas a serem discutidas na Roda, definidas como Ensino Remoto, Organização das Atividades Acadêmicas e Relação Orientando-Orientador. A respeito do último item, lançou-se a seguinte questão: "No que tange às vivências e experiências da turma PPG-ECIM/2020 de iniciar o mestrado em meio à Pandemia de Covid-19, o que você gostaria de discutir em uma roda de conversa?".

Após uma análise prévia, notou-se um interesse mais favorável à abordagem da temática “Organização das Atividades Acadêmicas”, com 37\% das respostas, seguida pelas temáticas "Ensino Remoto", com 26\%, e "Relação Orientando-orientador", correspondendo à 16\% do total das respostas enviadas à plataforma. No campo denominado "Outras Temáticas" (21\%), os mestrandos demonstraram-se a favor à abordagem conjunta das três temáticas fornecidas no questionário.

Em virtude disso, as mediadoras dialogaram entre si e planejaram a sistemática e roteiro para o desenvolvimento da Roda de Conversa, estabelecendo as três temáticas supramencionadas como eixos norteadores do diálogo. Ademais, vale ressaltar que no decorrer do processo de construção e planejamento da Roda, as mediadoras realizaram encontros remotos por intermédio de um grupo virtual criado no aplicativo para troca de mensagens WhatsApp - e, reuniões pelo Google Meet $^{8}$, atendendo às regras sanitárias de distanciamento social, decretadas no Estado do Amazonas, em virtude da pandemia.

A Roda requereu a instituição de "combinados" a priori, a fim assegurar que todos os participantes gozassem de vez e voz, oportunizando o processo dialógico preconizado por

\footnotetext{
${ }^{6}$ Aplicativo que permite realizar reuniões virtuais. Na Roda de Conversa, utilizou-se a versão por assinatura para realizar a gravação da chamada a partir da autorização dos participantes. Fonte: https://zoom.us/pt-pt/meetings.html.

${ }^{7}$ Aplicativo de gerenciamento da Plataforma Google for Education, no qual os usuários podem recolher informações por meio de questionários e formulários de registro. Fonte: https://www.google.com/intl/pt-BR/forms/about/.

${ }^{8}$ Serviço de comunicação por videochamada da Plataforma Google for Education. Fonte: https://meet.google.com/.
} 
Freire (2005), segundo o qual torna-se inevitável estabelecer as condições preliminares para um momento dialético profícuo, delineando a direção que ele deverá trilhar.

Em razão disso, tal participação se deu mediante às manifestações oralizadas - por intermédio do recurso digital, disponível na Plataforma Zoom Meetings, a "mãozinha digital"9 - e escritas - relato das dúvidas e posicionamentos no bate-papo da videochamada, acompanhado por duas mediadoras. Já os "combinados", estabelecidos antes de iniciar o diálogo, foram essenciais para o aproveitamento efetivo da conversa, dentre eles, cumpre destacar: "levantar a mão (virtualmente)"; participação pelo chat; microfones desligados; áudio silenciado enquanto outro participante vocaliza; câmeras abertas (ligadas); seleção de duas perguntas realizadas de maneira oralizada ao final de cada tópico e as demais via chat.

No mais, no que tange a dinâmica da roda, das seis mediadoras, que também são discentes do Programa, duas conduziram cada temática com o auxílio do PowerPoint, de forma que foram destinados 20 min para a abordagem de cada temática e 10 min para a discussão e reflexão dos questionamentos sinalizados.

\section{ANÁLISES E RESULTADOS}

Com o desenvolvimento da dinâmica, (re)conhecemos as potencialidades das trocas de experiências e o planejamento de ações com base na participação democrática. Apesar da disposição não ter ocorrido em círculo, do modo como seria em um encontro presencial, os sujeitos envolvidos manifestaram seus pontos de vistas, compartilharam suas angústias e dúvidas, acerca do processo formativo no Mestrado, de forma descontraída e flexível.

As temáticas estabelecidas entre pares, ou seja, de mestrando para mestrando, contribuíram para uma participação mais acentuada, mediante a questionamentos e esclarecimentos de indagações, tendo em vista, em consonância com as proposituras de Freire (2021), a horizontalidade entre os sujeitos. A partir disso, obteve-se um panorama das diversas realidades, nas quais os sujeitos estavam imersos, dado que surgiram questões tocantes ao desenvolvimento da dissertação, à organização de estudos em meio ao ensino remoto e conciliação com a vida familiar, acadêmica e social.

Nas discussões acerca do Ensino Remoto, foram abordados assuntos pertinentes às experiências e vivências das mediadoras com essa modalidade de ensino, englobando os seguintes pontos: preocupação e adaptação quanto ao desenvolvimento da pesquisa à pandemia

\footnotetext{
${ }^{9}$ Este recurso permite que o participante interaja com o organizador da reunião para alertá-lo se deseja contribuir com o assunto. Fonte: https://websetnet.net/pt/how-to-raise-a-hand-in-a-zoom-meeting/.
} 
Caderno de Pesquisa em Ensino

de Ciências e Matemática

e ao ensino remoto; uso das tecnologias digitais e plataformas gratuitas, como as do Google for Education, aliadas ao processo de adaptação; experiência relativa ao desdobramento do Estágio de Docência de modo virtual; aproveitamento dos cursos de extensão e eventos on-line; organização de encontros virtuais entre colegas e professores do Programa.

Em função disso, enfatizou-se a imprescindibilidade de (re)pensar os temas e as temáticas das pesquisas que seriam desenvolvidas, assim como o tipo de abordagem, estratégias de investigação, métodos de recolha e análise de dados, instrumentos e formas de registro a serem utilizados. Por conseguinte, recomendou-se o emprego das TICs - tais como aquelas que mais foram manuseadas pelas mediadoras para aprimorar a formação continuada e realizar um trabalho cooperativo em tempo real -, como as Redes Sociais (Instagram, YouTube e Facebook), Notas Adesivas ${ }^{10}$ e ferramentas da Plataforma Google for Education, como o Google Agenda, Google Docs, Google Drive e Google Forms.

Em relação às redes sociais, foram compartilhados vários perfis de Programas de Pósgraduação, cuja área de concentração versa o Ensino e a Educação, além de comentar-se a importância de conectar-se aos perfis de cunho científico, para reforçar a divulgação de eventos, lives e minicursos, os quais são ofertados virtualmente. No tocante aos recursos da Plataforma Google for Education, foram exemplificadas algumas de suas funcionalidades, considerando o uso dos aplicativos sugeridos, bem como suas contribuições para o processo formativo de pesquisadores iniciantes, relacionadas à gestão do tempo, identificação de prioridades e organização de materiais para leitura.

Diante disso, alguns dos discentes se posicionaram acerca de múltiplos recursos e aplicativos disponíveis, os quais podem ser utilizados no processo de ensino e aprendizagem. Nesse sentido, as TICs podem fortalecer a construção de competências e habilidades, como a autonomia, autoconfiança e autorresponsabilidade para com seu desenvolvimento formativo. Ao encontro dessa visão, sublinha-se que a Pandemia de Covid-19 tem acelerado a consolidação dessas tecnologias na aquisição do conhecimento, desencadeando outros modos de interações sociais, distintos dos padrões tradicionais institucionalizados, requerendo, consequentemente, uma reflexão acerca do papel do professor, assim como para sua formação inicial e continuada, a qual deve assegurar um espaço, no qual desenvolva/domine competências digitais docentes (DIAS-TRINDADE; SANTO, 2021).

10 Aplicativo da Microsoft para escrever anotações rápidas na área de trabalho do computador. Fonte: https://support.microsoft.com/pt-br/office/comece-a-usar-as-notas-autoadesivas. 
Outro questionamento recorrente diz respeito à preocupação sobre o que, como e onde pesquisar no regime virtual, tal como indagam os acadêmicos abaixo:

Mestrando (A): Qual estratégia o Programa está montando para os mestrandos ingressantes, sendo que não tem um método que irão utilizar online. Qual seria a ferramenta para utilizar? Tendo em vista a pandemia?

Mestrando (B): Como colaborar com o Ensino de Ciências e Matemática com pesquisas no contexto da pandemia?

Como respostas a essas interrogações, enfatizou-se a substancialidade de um olhar cuidadoso às escolhas metodológicas e lentes teóricas adotadas na pesquisa. Para tanto, recomendou-se atenção aos componentes curriculares ofertados pelo Programa, os quais: subsidiam a elaboração dos projetos de pesquisa; promovem discussões histórico-críticas e epistemológicas acerca do Ensino de Ciências; apresentam múltiplas teorias de aprendizagem, considerando a variável do contexto pandêmico. Tais apontamentos postulam que a formação continuada deve promover um ambiente, no qual o professor desenvolva e aprimore características de um profissional reflexivo, crítico, investigador e divulgador de um conhecimento científico vivo, atuante, democrático e conscientizador (CARVALHO; GILPÉREZ, 2011).

Por fim, nas discussões pertinentes a primeira temática, evidenciou-se a importância de instituir uma rede de apoio ao longo do mestrado. Tal rede respeita grupos de pessoas - seja do núcleo familiar ou profissional - que acompanham e apoiam o pesquisador ao longo da formação continuada. Nesse plano, torna-se essencial o educador tomar cuidado com sua saúde socioemocional e psicológica, partilhando suas ansiedades, preocupações e celebrações inerentes ao processo formativo, cujas relações precisam ser solidificadas à medida em que os estudos avançam (FREIRE, 2005).

Já na temática Organização das Atividades Acadêmicas, foram discutidos alguns tópicos que auxiliaram no desenvolvimento do Projeto de Pesquisa, das diversas disciplinas cursadas e demais atividades acadêmicas, abarcando os subtemas: Imersão Equilibrada ao longo do Mestrado; Humildade Acadêmica para aprender com os demais; Importância e Participação em Grupos de Pesquisa; Contribuição das disciplinas para o desenvolvimento da dissertação e no aprimoramento dos saberes e habilidades profissionais.

Nesse viés, outros dois aspectos mostraram-se relevantes para compor o debate relacionado à organização das atividades acadêmicas aliada ao ensino remoto: 1) Sujeito; 2) Coletividade. O primeiro concerne sua individualidade como pesquisador, com suas 
Caderno de Pesquisa em Ensino

de Ciências e Matemática

subjetividades e potencialidades, uma vez que o processo formativo trata-se de um exercício de autocuidado e autoconhecimento, vislumbrando-se como sujeito aprendiz em constante (des)(re)construção, aberto à imersão e harmonia entre a vida pessoal e acadêmica, considerando as complexidades que circundam a vida cotidiana (MORIN, 2005).

O segundo aspecto, alusivo à coletividade, tece a questão levantada pelo mestrando acerca da necessidade de buscar, coletivamente, empreender o caminho da constituição enquanto professor pesquisador:

Mestrando (C): Já existe um local em que a gente possa trocar as informações entre calouros e veteranos? Acho que seria interessante a gente conseguir ter mais contato uns com os outros [de forma coletiva] ou o contato é específico com uma pessoa?

Para tal indagação, em congruência com as indicações dos participantes da Roda, apontou-se a criação de um perfil para o Programa nas redes sociais, especificamente, no Instagram, além da elaboração de um grupo virtual em um aplicativo para trocas de mensagens, com vistas à composição de um ambiente pautado nas trocas de informações entre os membros de uma mesma turma. Ademais, também sinalizou-se que tais trocas poderiam ser fomentadas a partir da participação virtual nos Exames de Qualificação e Defesas de Dissertações, cujos convites são enviados, previamente, por e-mail, a todos os mestrandos do PPG-ECIM.

Ao encontro dessa ótica, a participação em Grupos de Pesquisa, também foi destacada como uma aliada no processo de formação do professor pesquisador. No chat, surgiram dúvidas pertinentes ao procedimento para inserção do mestrando em um Grupo de Pesquisa, sendo aconselhado, além da manifestação de interesse, um diálogo com o docente orientador, o qual pode indicar outros grupos, além do qual participa. Das potencialidades apresentadas, ressaltouse o aprofundamento nas áreas de Ensino de Ciências, o acesso à leitura de outras áreas, a experiência em arguições, as reflexões e os debates sobre determinados temas e a construção de uma rede cooperativa, a qual propicia parcerias com outros pesquisadores que têm interesses comuns em determinadas áreas e/ou temáticas (TEIXEIRA; PASSOS; ARRUDA, 2015).

Por fim, na temática Relação Orientando-orientador, foram debatidos aspectos que permeiam essa relação, bem como dicas de como torná-la mais profícua e algumas sugestões para a escolha do orientador, tecendo os seguintes itens: Análise do Currículo Lattes do possível orientador; Atenção ao feeling da conversa primária; Diálogo com ex-orientandos; Diálogo constante com o orientador; Respeito e Conhecimento dos limites da relação; Desenvolvimento da autonomia. 
Nessa perspectiva, alguns acadêmicos levantaram indagações alusivas à escolha do orientador. As mediadoras compartilharam a experiência de participar, ativamente, das

palestras proferidas por cada um dos docentes orientadores, de acordo com a linha de pesquisa, durante a semana de acolhida do Programa para calouros, a fim de verificar aqueles que mais se identificam. No mais, para além das questões burocráticas necessárias ao vínculo acadêmico entre orientando-orientador, cumpre salientar outros pontos julgados, no decorrer das arguições, como imprescindíveis ao desenvolvimento dessa relação, tais como: ouvir atentamente; capacidade de negociação; disciplina; autodependência; autoeficácia; automotivação (FREIRE, 2021).

Em conclusão, antes de finalizar o diálogo, as mediadoras realizaram uma recapitulação dos principais pontos abordados na Roda de Conversa e realçaram alguns pontos que tornaramse essenciais para o desenvolvimento salutar no mestrado, cumprindo sublinhar: a inevitabilidade da construção de uma rotina de estudos; o estabelecimento de metas diárias e exequíveis; a dedicação contínua; leitura diária; anotações frequentes consideradas úteis; o respeito ao próprio ritmo; a atenção aos prazos; a familiarização com recursos e artifícios digitais.

Perante as elucidações, tais sugestões traduzem-se na tentativa, tal como advogam Morin (2005) e Carvalho e Gil-Pérez (2011), de contribuir com a formação e consolidação de um professor pesquisador que compreenda a obrigatoriedade de reinventar e adequar-se às múltiplas realidades e situações complexas subjacentes e adjacentes à sociedade, à Educação e ao Ensino de Ciências. Desse modo, as novas necessidades requerem uma ação reflexiva, analítica e contextualizada para enfrentar os desafios oriundos da Pandemia de Covid-19.

\section{CONSIDERAÇÕES FINAIS}

O emprego da Roda de Conversa, como um instrumento metodológico, favoreceu a interação entre os mestrandos, dado que o grupo se sentiu à vontade para relatar vivências, experiências, concepções, anseios, perspectivas e questionamentos de maneira informal. Em conclusão, difundiu-se um espaço - possível de ser realizado, apesar do cenário pandêmico para participação democrática entre os diferentes saberes por meio de uma plataforma digital-, valorizando-se a cultura de trocas e diálogo, tão necessária à formação do professor pesquisador durante todo o seu processo formativo, bem como à prática em sala de aula, tendo em vista um Ensino de Ciências inclinado ao desenvolvimento da criticidade e reflexão dos indivíduos. 
Caderno de Pesquisa em Ensino

de Ciências e Matemática

Em decorrência disso, acerca do papel da reflexão na formação e prática do professor pesquisador, discutiu-se também os mecanismos pelos quais um professor de Ciências, ingressante em um mestrado da área, pode trilhar para desenvolver sua pesquisa, atentando-se, de forma crítica, harmônica e coerente, aos contextos complexos - socioculturais, históricoepistemológicos e político-filosóficos -, nos quais está imerso. Haja vista, tornou-se imprescindível inserir, nessa discussão, as problemáticas oriundas da pandemia de Covid-19 e seus impactos no desenvolvimento das pesquisas, particularmente, nas alusivas ao Ensino de Ciências, sobre as quais muitas provocações são lançadas no que tange o papel das TICs, à formação de professores e os processos de ensino e aprendizagem.

Do exposto, vislumbrou-se compartilhar aprendizados pertinentes à necessidade de realizar movimentos de reflexão, não somente em termos epistêmicos e metodológicos, contudo, especialmente, pedagógicos e ontológicos, atrelando o desenvolvimento profissional do professor pesquisador em Ensino de Ciências às múltiplas dimensões que o constituem. Portanto, por intermédio dos diálogos estabelecidos, buscou-se conduzir os participantes, de maneira responsiva, à complexidade das esferas, nas quais atua e atuará, considerando a sala de aula e o currículo de Ciências como molas propulsoras, posto que, ao mesmo tempo, intersectam dilemas sociais, nos quais o trabalho reflexivo e crítico do professor se faz urgente.

\section{REFERÊNCIAS}

ALVES-MAZZOTTI, A. J.; GEWANDSZNAJDER, F. O método nas ciências naturais e sociais: pesquisa quantitativa e qualitativa. 2. ed. São Paulo: Pioneira Thomson Learning, 2000 .

ARRUDA, G. Q. de; SILVA, J. S. R. de; BEZERRA, M. A. D. O uso da tecnologia e as dificuldades enfrentadas por educadores e educandos em meio a pandemia. In: VII

Congresso Nacional de Educação. Anais do VII Congresso Nacional de Educação, 2020. Disponível em:

https://editorarealize.com.br/editora/anais/conedu/2020/TRABALHO_EV140_MD1_SA_ID2 426_04092020084651.pdf. Acesso em: 09 jun. 2021.

CACHAPUZ, A. et al. A necessária renovação do Ensino das Ciências. 3.ed. São Paulo: Cortez, 2005.

CARVALHO, A. M. P. de; GIL-PÉREZ, Daniel. Formação de professores de ciências. 10. ed. São Paulo: Cortez, 2011.

CASTRO, E. L.; BARROS, M. K.; BARRETTO, R. F. A pesquisa científica sob a ótica do pensamento complexo e multidimensional de Edgar Morin. In: Conferência Internacional Saberes para uma Cidadania Planetária. Anais da Conferência Internacional Saberes para uma Cidadania Planetária, 2016. Disponível em:

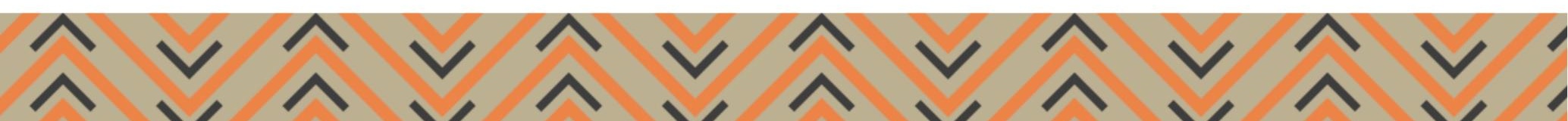


http://uece.br/eventos/spcp/anais/trabalhos_completos/247-38768-31032016-171011.pdf.

Acesso em: 09 jun. 2021.

COSTA, F. R. da S. et al. As visões distorcidas da natureza da ciência sob o olhar da História e Filosofia da Ciência: uma análise nos anais dos ENEQ e ENEBIO de 2012 e 2014. ACTIO: Docência em Ciências, v. 2, n. 2, p. 4-20, 2017. http://dx.doi.org/10.3895/actio.v2n2.6808.

DIAS-TRINDADE, S.; SANTO, E. do E. Competências digitais de docentes universitários em tempos de pandemia: análise da autoavaliação DIGCOMPEDU. Práxis Educacional, v. 17, n. 45, p. 1-17, 2021. https://doi.org/10.22481/praxisedu.v17i45.8336.

FREIRE, P. Pedagogia do Oprimido. 42. ed. Rio de Janeiro: Paz e Terra, 2005.

Pedagogia da Autonomia: saberes necessários à prática educativa. 67. ed. Rio de Janeiro/São Paulo: Paz e Terra, 2021.

GATTI, B. A. Grupo focal na pesquisa em Ciências Sociais e Humanas. Brasília: Liber Livros, 2005.

MASSONI, N. T.; MOREIRA, M. A. A visão Etnográfica de Bruno Latour da Ciência Moderna e a Antropologia Simétrica. RBECT, v. 10, n. 3, p. 61-80, 2017.

http://dx.doi.org/10.3895/rbect.v10n3.3776.

MISHRA, P.; KOEHLER, M. J. Technological Pedagogical Content Knowledge: A

Framework for Teacher Knowledge Teachers. College Record, v. 108, n. 6, p. 1017- 1054, 2006. Disponível em: http://one2oneheights.pbworks.com/f/MISHRA_PUNYA.pdf. Acesso em: 09 jun. 2021.

MORIN, E. Ciência com consciência. 8. ed. Rio de Janeiro: Bertrand Brasil, 2005.

SCHÖN, D. A. Educando o profissional reflexivo: um novo design para o ensino e a aprendizagem. Porto Alegre: ARTMED, 2000.

SONNEVILLE, J. J.; JESUS, F.P. Complexidade do ser humano na formação de professores. In: NASCIMENTO, A. D.; HETKOWSKI, T. M. (Org.). Educação e contemporaneidade: pesquisas científicas e tecnológicas. Salvador: EDUFBA, 2009. Disponível em: http://books.scielo.org/id/jc8w4/pdf/nascimento-9788523208721-14.pdf. Acesso em: 09 jun. 2021.

TARDIF, M. Saberes docentes e formação profissional. 12. ed. Petrópolis: Vozes, 2011.

TEIXEIRA, L. A.; PASSOS, M. M.; ARRUDA, S. M. A formação de pesquisadores em um grupo de pesquisa em Educação em Ciências e Matemática. Ciência \& Educação (Bauru), v. 21, n. 2, p. 525-541, 2015. http://dx.doi.org/10.1590/1516-731320150020016.

WARSCHAUER, C. A Roda e o Registro: Uma parceria entre professores, alunos e conhecimento. 5. ed. São Paulo: Paz e Terra, 2017. 
Submetido em: 10 de junho de 2021.

Aprovado em: 21 de junho de 2021.

Publicado em: 07 de julho de 2021.

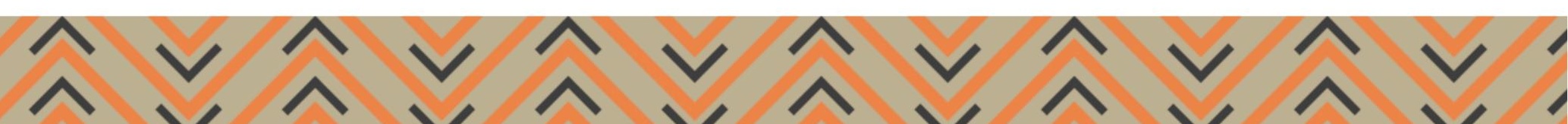

